\title{
ISOTOPIC FRACTIONATION OF NORWEGIAN MATERIALS FOR RADIOCARBON DATING
}

\author{
STEINAR GULLIKSEN
}

Radiological Dating Laboratory, The Norwegian Institute of Technology, Trondheim, Norway

ABSTRACT. To improve reporting of radiocarbon dates, Stuiver and Polach (1977) recommend that reported standard errors should include the error in the applied $\delta^{13} \mathrm{C}$ value, and suggest estimated mean values for $\delta^{13} \mathrm{C}$ to be applied when not measured. Based on $\delta^{13} \mathrm{C}$ data for ca 250 samples measured during 1975-1979, mean values for different materials dated by the Trondheim radiocarbon laboratory have been compiled. All material is from Norway and Svalbard (marine bone collagen). For peat, piled. All material is from None material, $\delta^{13} \mathrm{C}$ should be measured to obtain optimal gyttja, and terrestrial bone material, $\delta^{15} \mathrm{C}$ should be measured to obtain optine charcoal, and marine bones, the standard error in an estimated $\delta^{13} \mathrm{C}$ value will only increase uncertainty of a date from \pm 50 years to ca \pm 55 years.

\section{INTRODUCTION}

The use of radiocarbon dates for resolving fine chronologic structures has been increasing during recent years and, consequently, precision of dates is a subject more discussed than ever. Main topics are suitability of different types of sample materials and optimal dendrochronologic calibration curves. Essential for the evaluation of the accuracy of a date is, however, that no doubt exists about how a reported ${ }^{14} \mathrm{C}$ age is related to the ${ }^{14} \mathrm{C}$ activity of the sample. Pointing out that variations exist between reporting procedures used by different laboratories, Stuiver and Polach (1977) recommend a standard procedure for reporting ${ }^{14} \mathrm{C}$ data. One vital point is that corrections for isotopic fractionation must always be included, either by measured or estimated $\delta^{13} \mathrm{C}$ values. Reported standard errors shall, in addition to errors related to determination of ${ }^{14} \mathrm{C}$ activity of the sample, include error in the fractionation correction. They suggest estimated mean values for $\delta^{13} \mathrm{C}$ and appropriate errors for these estimates. Suggested errors will for most types of sample material give a considerable increase in reported ${ }^{14} \mathrm{C}$ errors, and optimal dating results will obviously be obtained only if ${ }^{13} \mathrm{C}$ is measured. To compare the suggested values with $\delta^{13} \mathrm{C}$ values obtained for Norwegian dating materials, data for ca 250 samples measured during 1975-79 were tabulated. The results are given below.

$$
{ }^{1: C} \text { measurements }
$$

Ten cc aliquots of $\mathrm{CO}_{2}$ sample gases were analyzed for mass 44/45 ratios by $\mathrm{R}$ Ryhage, Karolinska Institutet, Stockholm. Ratios were compared with those obtained for a substandard (T-176) used by our laboratory since 1960 . The substandard was precisely related to PDB in 1976 by W G Mook, Groningen, and in 1978 by A B Muller, University of Arizona. In close agreement, these measurements gave mean values

$$
\begin{aligned}
\delta^{13} \mathrm{C}_{\mathrm{T}-176 / \mathrm{PDB}} & =-2.8 \% \\
\delta^{18} \mathrm{O}_{\mathrm{T}-176 / \mathrm{PDB}} & =-23.5 \%
\end{aligned}
$$


Based on equations and isotopic ratios given by Craig (1957), these values give for correction of measured mass ratios $\left(\delta_{\mathrm{m}}\right)$ :

$$
\delta^{13} \mathrm{C}=1.0670 \delta_{\mathrm{m}}-0.0335 \delta^{18} \mathrm{O}
$$

Conversion to PDB scale is then done the usual way, and all $\delta^{13} \mathrm{C}$ values given in this paper are relative to PDB. Accuracy of $\delta^{13} \mathrm{C}$ values is ca $\pm 0.5 \%$.

\section{Sample treatment}

As chemical processing of sample materials can cause slight isotopic fractionation, it is necessary to consider the methods of processing samples when comparing $\delta^{13} \mathrm{C}$ data from different laboratories.

Chemical pretreatment. 1) Wood, charcoal, peat: 5 percent $\mathrm{HCl}$ and 5 percent $\mathrm{NaOH}$ at $90^{\circ} \mathrm{C}$, each for 5 min. 2) Gyttja, dy: either 5 percent $\mathrm{HCl}$ at $90^{\circ} \mathrm{C}$ for $5 \mathrm{~min}$ or extraction of soluble fraction by 10 percent $\mathrm{NaOH}$ at $90^{\circ} \mathrm{C}$ for $3 \mathrm{hr}$. Insoluble precipitated with concentrated $\mathrm{HCl}$. 3) Bone: inorganic fraction removed with 25 percent $\mathrm{HCl}$ under vacuum (3-20 hr). Five percent $\mathrm{NaOH}$ (cold) for $5 \mathrm{~min}$. Collagen separated by dissolution in slightly acidic ( $\mathrm{pH} 3.0$ ) water at $90^{\circ} \mathrm{C}$. 4) Shell. Dissolved in $\mathrm{HCl}, 10$ to 20 percent of surface removed with diluted $\mathrm{HCl}$.

Combustion, purification. Combustion in quartz tubes, sample contained in inner tube. Completion assured by platinum catalyst and $\mathrm{CuO}$ oven. Sample gas passing $\mathrm{KMnO}_{4}$ traps and absorbed directly in $\mathrm{NH}_{3}$, precipitated as $\mathrm{CaCO}_{3}$, washed and re-evaporated with $\mathrm{H}_{3} \mathrm{PO}_{4}$. Distilled twice through $\mathrm{Cu}-\mathrm{CuO}$ ovens.

\section{RESULTS AND DISCUSSION}

The histograms in figures $1-5$ show the distribution of $\delta^{13} \mathrm{C}$ values around the mean values for different sample materials. Gauss curves are drawn according to the standard deviation for each group.

Wood and wood charcoal samples (fig 1 ) have a mean $\delta^{13} \mathrm{C}$ value of $-26.1 \%$ with a group standard deviation of $1.3 \%$. The average is slightly lower than the value $-25 \%$ adopted for wood, which also is suggested as a best estimate for recent wood by Stuiver and Polach (1977). This value is based on measurements done by Craig (1953; 1954; 1957) on material from geographically widespread locations. The estimate for fossil wood is based mainly on wood older than 11,000 years BP, and is consequently not applicable for Holocene samples.

The low $\delta^{13} \mathrm{C}$ content of the Norwegian wood is not in opposition to a possible temperature effect. The low yearly mean temperature in Norway should eventually give atmospheric carbon dioxide a lighter isotopic composition than the average for various locations investigated by Craig.

Species have been determined for 28 of the wood and charcoal samples. Table 1 lists the results. Agreement with samples measured by Olsson and Osadebe (1974) is reasonable. Two measurements on pine from Sweden by Lerman and others (1970) also agree, which averaged 
TABLE 1

$\delta^{13} \mathrm{C}$ values for wood and charcoal of different species. Last two columns refer to Olsson and Osadebe (1974).

\begin{tabular}{lcccc}
\hline \multicolumn{1}{c}{ Species } & Samples & $\begin{array}{c}\delta^{13} \mathrm{C}(\%) \\
\text { mean value }\end{array}$ & Samples & $\begin{array}{c}\delta^{13} \mathrm{C}(\%) \\
\text { mean value }\end{array}$ \\
\hline Birch (Betula) & 7 & -27.5 & 2 & -27.1 \\
Willow (Salix) & 3 & -26.3 & 1 & -27.0 \\
Hazel(Corylus) & 2 & -27.1 & & \\
Oak (Quercus) & 1 & -26.8 & 1 & -24.0 \\
Alder(Alnus) & 1 & -25.3 & & -24.7 \\
Larch (Larix) & 7 & -25.1 & 4 & -24.7 \\
Pine (Pinus) & 4 & -24.4 & 9 & -23.3 \\
Spruce (Picea) & 3 & -25.7 & 3 & 3 \\
\hline
\end{tabular}

$-25.1 \%$. The results may indicate that Nordic conifers are slightly richer in ${ }^{13} \mathrm{C}$ than the deciduous species, but more data is needed to decide whether the difference could be significant.

For peat and gyttja samples (fig 2) the mean $\delta^{13} \mathrm{C}$ value was $-27.7 \%$, with a group standard deviation of $3.4 \%$. As most Nordic peat consists of remains of plants whose carbon assimilation follows the Calvin $\left(\mathrm{C}_{3}\right)$ pathway of photosynthesis, a value of ca $-27 \%$ was expected (Lerman, 1972; Troughton, 1973). The range and distribution of the $\delta^{13} \mathrm{C}$ values are in excellent agreement with that given by Troughton (1973) for 250 different species of plants. The estimate given by Stuiver and Polach (1977) is also $-27 \%$. Both $\mathrm{NaOH}$-soluble and insoluble fractions were measured for several gyttja samples. Difference between fractions was not significant, and the average value is used.

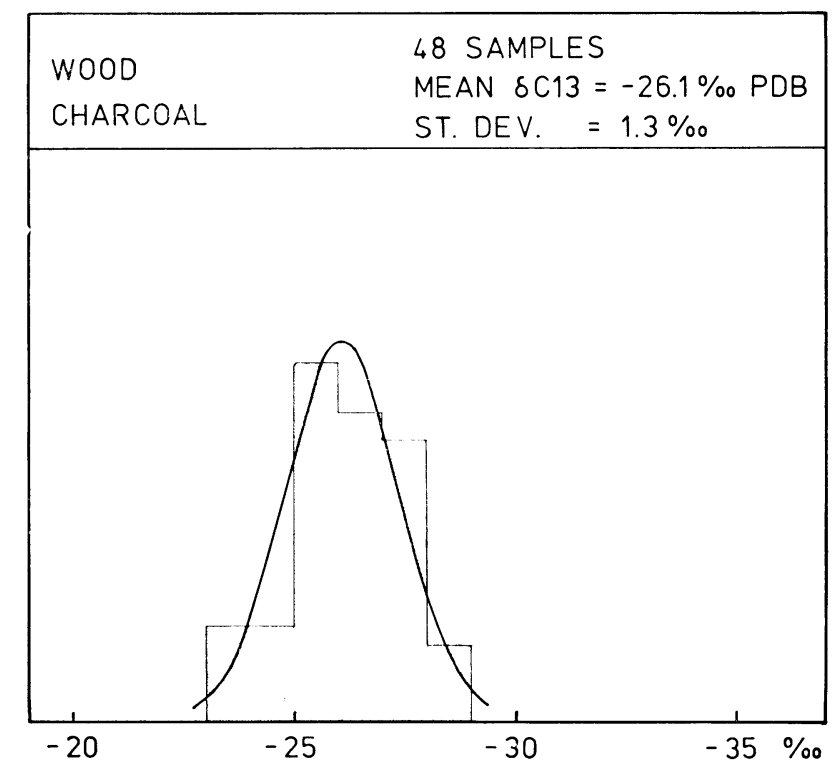

Fig 1. Distribution of $\delta^{13} \mathrm{C}$ values in per mil relative to PDB for 48 samples of wood and wood charcoal. The solid line is the corresponding Gaussian distribution. 
For collagen derived from bones of terrestrial animals, a mean value of $-21.7 \%$ was obtained, and the standard deviation is $3 \%$ (fig 3 ). The diet must have been mainly $\mathrm{C}_{3}$ plants; thus the enrichment of $+6 \%$ o by animal metabolism suggested by Lerman (1972) is confirmed by our data. The great range found for plant remains is reflected in the spread of $\delta^{13} \mathrm{C}$ in terrestrial bone collagen.

The values around $-15 \%$ was from two samples of Homo sapiens, one was 7000 years BP. Both are from coastal areas, and the high ${ }^{13} \mathrm{C}$ content was probably caused by an extremely fishy diet. The estimate suggested by Stuiver and Polach (1977) is $-20 \%$.

Marine shell samples (fig 4) have a mean value of $+1.0 \%$ and a standard deviation of only $1.0 \%$. The result agrees with the mean value $+0.8 \%$ which was obtained for 16 samples of recent shells from Norway (Mangerud and Gulliksen, 1974). Measurements by Olsson and Osadebe (1974) on more than 50 samples indicate, however, a mean value of $-0.7 \%$, while the mean value for 10 shell samples from West Greenland is $+1.5 \%$ (Donner and Jungner, 1975). Stuiver and Polach (1977) suggest $0 \%$ for shell carbonate.

Bone collagen from marine animals (fig 5) is mainly whale samples from Svalbard. Mean value is $-16.4 \%$ and standard deviation $1.1 \%$. Olsson and others (1974) concludes that whale bone collagen is ca $17.0 \%$.

\section{Age correction}

The mean $\delta^{13} \mathrm{C}$ values obtained should be fairly representative for isotopic fractionation in Norwegian materials for radiocarbon dating. Thus, table 2 lists our estimate for samples with unknown ${ }^{13} \mathrm{C}$ content.

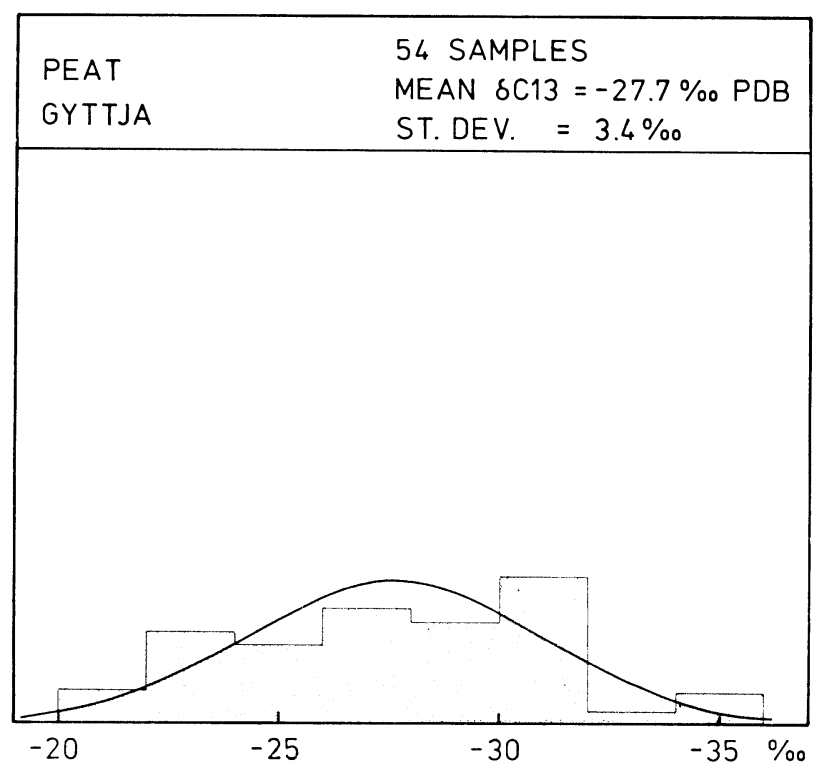

Fig 2. Distribution of $\delta^{13} \mathrm{C}$ values in per mil relative to PDB for 54 samples of peat and gyttja. The solid line is the corresponding Gaussian distribution. 


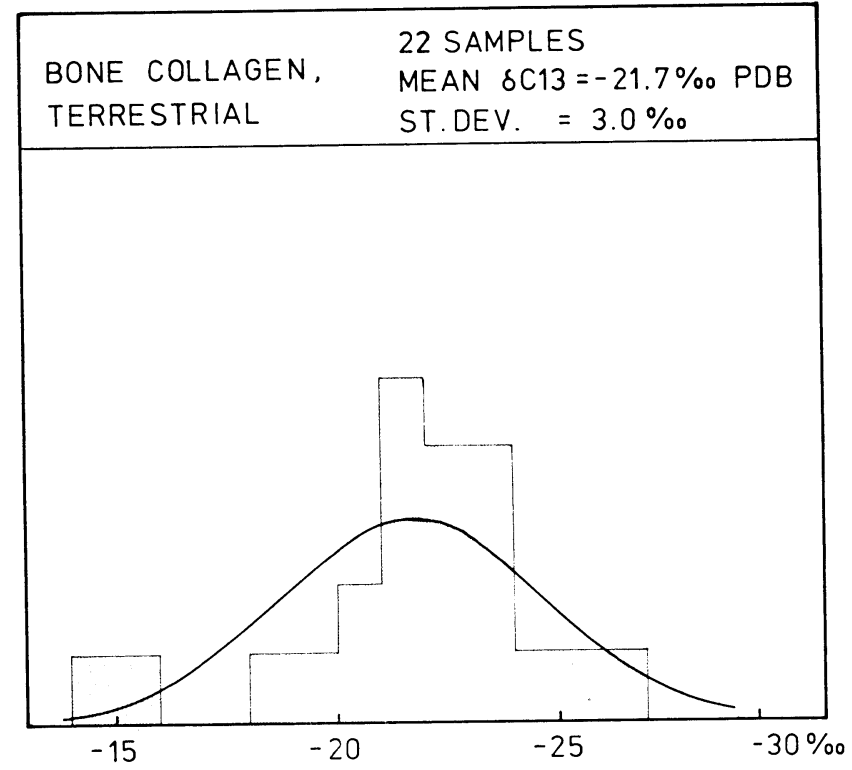

Fig 3. Distribution of $\delta^{13} \mathrm{C}$ values in per mil relative to $\mathrm{PDB}$ for 22 samples of bone collagen from terrestrial animals. The solid line is the corresponding Gaussian distribution.

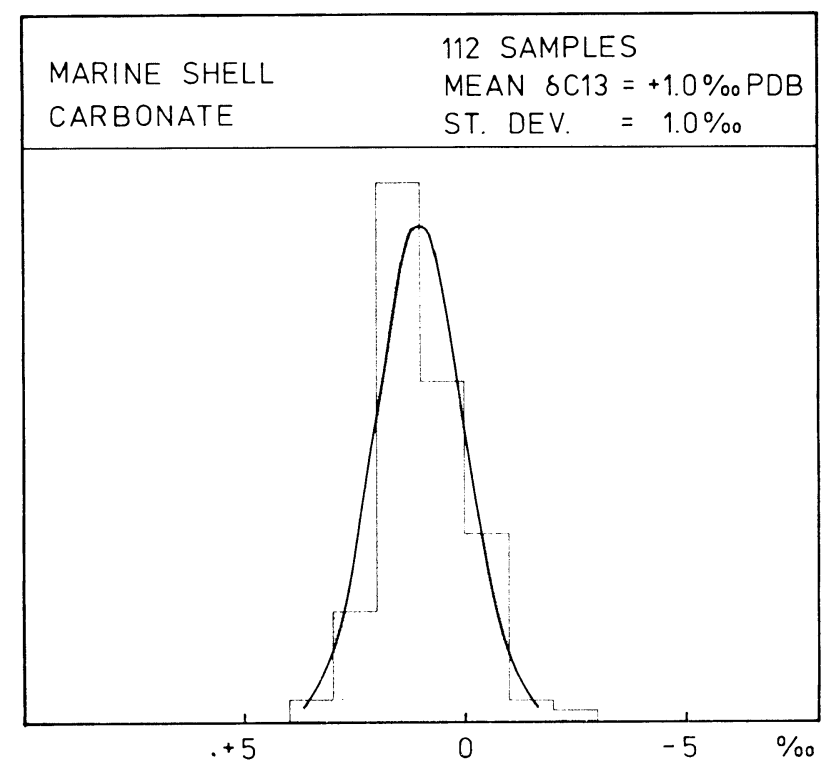

Fig 4. Distribution of $\delta^{13} \mathrm{C}$ values in per mil relative to PDB for 112 samples of carbonate from marine shells. The solid line is the corresponding Gaussian distribution. 
TABLE 2

Estimates for $\delta^{13} \mathrm{C}$ values of different Norwegian materials for radiocarbon dating, and corresponding age correction. Last column refers to age corrections suggested by Stuiver and Polach (1977).

\begin{tabular}{lcccc}
\hline \multicolumn{1}{c}{ Material } & Samples & $\begin{array}{c}\delta^{13} \mathrm{C}(\%) \\
\text { estimate }\end{array}$ & $\begin{array}{c}\text { Age correction } \\
\text { years }\end{array}$ & $\begin{array}{c}\text { Age correction } \\
\text { years }\end{array}$ \\
\hline $\begin{array}{l}\text { Wood, charcoal } \\
\begin{array}{l}\text { Peat, gyttja } \\
\text { Bone collagen, } \\
\text { terrestrial }\end{array}\end{array}$ & 48 & $-26.1 \pm 1.3$ & $-20 \pm 20$ & $0 \pm 70$ \\
$\begin{array}{l}\text { Shell carbonate, } \\
\text { marine }\end{array}$ & 54 & $-27.7 \pm 3.4$ & $-45 \pm 55$ & $-35 \pm 95$ \\
$\begin{array}{l}\text { Bone collagen, } \\
\text { marine }\end{array}$ & 112 & $-21.7 \pm 3.0$ & $55 \pm 50$ & $80 \pm 35$ \\
\hline
\end{tabular}

The table also gives the corresponding age corrections for radiocarbon dates, and those suggested by Stuiver and Polach (1977). Differences are small and not significant. They indicate, however, slightly lighter isotopic composition in the Nordic terrestrial environment, while marine carbonate is on the heavy side.

The error of estimation in table 2 is the group standard deviation, which is correct assuming that distribution of $\delta^{13} \mathrm{C}$ values is Gaussian. This is a reasonable approximation (fig 1-5), and the given error for age corrections should be added to the standard deviation of the uncorrected age by taking root-sum-of-squares. The correction errors given by Stuiver

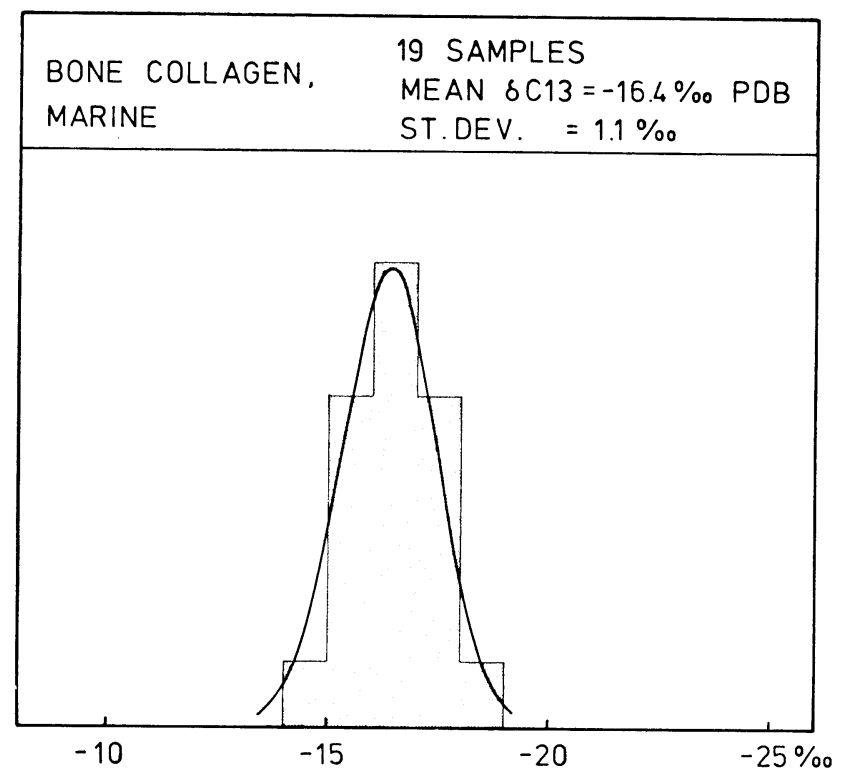

Fig 5. Distribution of $\delta^{13} \mathrm{C}$ values in per mil relative to PDB for 19 samples of bone collagen from marine animals. The solid line is the corresponding Gaussian distribution. 
and Polach (1977) are considerably larger, except for terrestrial bones, and corresponds with the total range of $\delta^{13} \mathrm{C}$ values. Alternatively, suggested appropriate errors of estimation for $\delta$ values are smaller than the total range (Stuiver and Polach, 1977, fig 1, p 358), and it is not quite clear which errors are to be included in the reported standard error of the date.

\section{CONCLUSION}

In peat, gyttja, and bone collagen variability of isotopic fractionation is so large that ${ }^{13} \mathrm{C}$ content should be measured to avoid a significant contribution to dating uncertainty. For wood, charcoal, and marine shell carbonate, use of estimated $\delta^{13} \mathrm{C}$ values is acceptable and will give only a small increase in the uncertainty of a date.

\section{ACKNOWLEDGMENTS}

The author wishes to thank the staff of the laboratory, and in particular Fred Skogseth, for valuable assistance. The work was financially supported by The Norwegian Research Council for Science and the Humanities (NAVF).

\section{REFERENCFS}

Craig, Harmon, 1953, The geochemistry of the stable carbon isotopes: Geochim et Cosmochim Acta, v 8, p 53-92.

1954, Carbon-13 in plants and the relationships between carbon-13 and 14 variations in nature: Jour Geology, v 62, p 115-149.

1957, Isotopic standards for carbon and oxygen and correction factors for mass-spectrometric analysis of carbon dioxide: Geochim et Cosmochim Acta, v 12, p 133-140.

Donner, Joakim and Jungner, Högne, 1975, Radiocarbon dating of shells from marine Holocene deposits in the Disko Bugt area, West Greenland: Boreas, v 4, p 25-45.

Lerman, J C, 1973, Carbon-14 dating: Origin and correction of isotope fractionation errors in terrestrial living matter, in Rafter, $\mathrm{T}$ A and Grant-Taylor, $\mathrm{T}$, eds, Internatl radiocarbon conf, 8th, Proc: Wellington, New Zealand, Royal Soc New Zealand, H16-H28.

Lerman, J C, Mook, W G, and Vogel, J C, 1970, C ${ }^{14}$ in tree rings from different localities, in Olsson, I U, ed, Radiocarbon variations and absolute chronology, Nobel symposium, 12th, Proc: New York, John Wiley \& Sons, p 275-301.

Mangerud, J and Gulliksen, Steinar, 1974, Apparent radiocarbon ages of recent marine shells from Norway, Spitsbergen, and Arctic Canada: Quaternary Research, v 5, p 263-273.

Olsson, I U and Osadebe, F A N, 1974, Carbon isotope variations and fractionation corrections in ${ }^{14} \mathrm{C}$ dating: Boreas, v 3, p 139-146.

Olsson, I U, El-Daoushy, M F, Abd-El-Mageed, Abdella, and Klasson, Martin, 1974, A comparison of different methods for pretreatment of bones. I: Geol Fören Stockh Förh, v 96, p 171-181.

Stuiver, Minze and Polach, H A, 1977, Discussion: Reporting of ${ }^{14} \mathrm{C}$ data: Radiocarbon, v 19, p 355-363.

Troughton, J H, 1973, Carbon isotope fractionation by plants, in Rafter, $\mathrm{T} A$ and Grant-Taylor, $T$, eds, Internatl radiocarbon conf, 8th, Proc: Wellington, New Zealand, Royal Soc New Zealand, E39-E57. 